\title{
Family Caregivers Perceptions of Palliative Care in Home and Unit: The Balance between Given and Received Support
}

\author{
Sabrina Lessard ${ }^{1 *}$, Bernard-Simon Leclerc ${ }^{1,2,3}$ and Suzanne Mongeau ${ }^{1,4}$ \\ ${ }^{1}$ Research Centre, Centre for Health and Social Services Bordeaux-Cartierville-Saint-Laurent, university-affiliated center, 11822 Avenue du Bois-de- \\ Boulogne, Montreal (Quebec) H3M 2X6, Canada \\ ${ }^{2}$ Department of Social and Preventive Medicine, Faculty of Medicine, University of Montreal, PO Box 6128, Station Centre-Ville, Montreal (Quebec) H3C \\ 3J7, Canada \\ ${ }^{3}$ Research Centre, University Institute of Geriatrics of Montreal, 4565 Queen Mary Road, Montreal (Quebec), H3W 1W5, Canada \\ ${ }^{4}$ École of Social Work, University of Quebec at Montreal, 455 boul. René-Lévesque Est, Montreal (Québec) H2X 4Y2, Canada
}

Received: August 07, 2014; Accepted: October 28, 2014; Published: November 03, 2014

*Corresponding author: Sabrina Lessard, Research Centre for Health and Social Services Bordeaux-Cartierville-Saint-Laurent, university-affiliated center, 11822, Avenue du Bois-de-Boulogne, Montreal (Quebec) H3M 2X6, Canada, Tel: +1-514-331-2288 ext. 4057; E-mail: sabrina.lessard.bcstl@ssss. gouv.qc.ca

\begin{abstract}
Background: Family caregivers providing care to a terminally ill person are affected by the challenge of providing care at the endof-life stage. A palliative approach can differently mark the end-oflife experience for the caregiver, according to the kind of given and received social support. We searched to increase our understanding of what could influence the perceived experience of care by caregivers.

Methods: This study focused on the experience of family caregivers, using a qualitative method, in regard to their perceptions of given and received social support from formal and informal sources while caring for a terminally ill person in different settings and trajectories of care, in home care or a specialized unit. Participants were 23 caregivers who cared for end-of-life patients at home and/ or in a specialized palliative care unit. Semi-structured face-to-face interviews were performed 3 to 6 months later and the data gathered were then qualitatively analyzed using an inductive grounded theory approach.
\end{abstract}

Results: The results show that caring for a terminally ill person requires continuous balancing between given and received support to ease the caregiver's experience. Analysis has identified the aspects affecting the balance between given and received social support and the ability of the caregiver to keep a positive perception of the lived experience.

Conclusion: Finding revealed that family caregivers seem to cope better if they perceived sufficient social support during the caring period. These findings might be useful in the continuous improvement of training for different settings in palliative care and to focus on identifing the needs of caregivers.

Keywords: Family caregivers; End-of-life care; Palliative care; Qualitative research; Social support

\section{Introduction}

In past decades, efforts were made to implement the shift to ambulatory care and to reduce the length of hospital stays in the province of Quebec, Canada, as elsewhere in industrialized countries. Following the reorganisation of the health system, certain responsibilities previously assumed by the state have been transferred to other social actors, especially to patients and their families [1,2]. This shift reinforced a "dumbing-down" of care [1] and assumed that health care can be managed by ordinary people. In reality, it seems to be more complex for the patient and their family caregivers than it is for a professional careworker. A study [3] showed that only $8 \%$ of the required services at home are provided by the public health system in Quebec, while 70\% are provided by the family caregivers.

Palliative care services have also been touched by this reform. Patient needs and choices vary widely and a broad range of services is often sought in diverse settings, from patients' homes to specialized palliative care units. The state's shift from institutional to community care supports the preference of many patients to die in their own homes [4,5]. Nevertheless, family caregivers looking after a terminally ill person are profoundly affected by the challenge of providing care at the end-oflife stage. According to studies focused on family caregivers' experience, the burden of care is important [4,6-8]. This challenge encompasses the management of physical care, practical daily living activities and emotional support while handling their own emotional distress about the care and concerns of the loss of the terminally ill person $[4,7,9]$. Their abilities and resources are not always sufficient to meet these needs. Some studies suggest that sufficient social support received during stressful situations as the end-stage illness enhances family caregivers' capacity to cope $[7,9-12]$. A palliative approach can differently mark the end-of-life experience according to given and received social support $[13,14]$ if related to specific needs $[12,15]$.

\section{Organization of Palliative Care Services}

Palliative care services in Canada are governed by the 
provinces and vary across the country in terms of setting, range of services and cost $[16,17]$. However, there are pan-Canadian standards and norms of practice for palliative services as personfamily centred approach, high quality and accessible services, team based care etc. [18]. In Quebec, there are four different settings providing palliative care: 1 ) the home; 2 ) hospitals; 3 ) residential and long term care centres (CHSLDs); and 4) specialized unit of palliative care (hospice). The local community service centres (CLSCs) also offer palliative care support to outpatients in the endof-life phase and their families to keep them as long as possible in their home environment. These services vary geographically and many patients are still quickly referred to hospitals when health conditions deteriorate. Home care services can also be provided by for-profit or non-profit organizations. About 20 hospitals have set a number of beds (about 140 in total) reserved for people in need of end-of-life care [16]. Palliative care services in CHSLD are not well developed in Quebec. In the vast majority of these institutions, only a few palliative care beds have been set aside $[16,19]$. Finally, not many specialized units (hospices) exist for palliative care support across Québec.

The available services are usually for cancer patients admitted with 3 months or less of vital prognosis [16]. The composition of the medical team and the type of services offered varies from one place to another. Ideally, care would be provided in a holistic approach by interdisciplinary teams composed of nurses, social workers, physicians, pharmacists, nutritionists, psychologists, occupational therapists, spiritual advisers and volunteers $[16,17]$. These teams offer a combination of interventions aimed at relieving suffering and improving quality of life of the patient and their family in the end-of-life process [20].

\section{Social Support}

Since the seventies, social support has been defined in a different way [10]. It is defined as the perception of available assistance from others that helps one to perceive oneself as valued, respected, trusted and loved [21,22]. For the purpose of this study, we reported the definition of social support as the social interaction which enhances the capacity to cope, the self-esteem and the competence of the caregivers through the real or perceived exchange of practical or emotional resources [23]. Some studies in palliative care have highlighted three fundamental dimensions of social support to meet the needs of family caregivers $[10,24,25]$ : (1) emotional, within the provision of care, empathy, love and trust; (2) instrumental, which is the action to help with daily tasks and/or specialized acts of care; and (3) informational, which includes information to solve problems [20-22]. According to Semmer et al. [25], instrumental support may also contain emotional meaning. In some situations, emotional support outweighs all other types of support. Social support is generally provided by informal sources like spouses, family, friends and colleagues and formal sources such as medical, health and social professionals and hands-on caregivers (nursing assistants, patient assistants, and volunteers) [12,21,23].

The concept of given and received ${ }^{1}$ social support can be

1 "Given" and "received" are action terms apropos the caregivers, while "formal" better understood as a social interaction closely related to its specific context [10]. Some authors show that the perception of the balance between giving and receiving social support has a positive effect on the recipient $[9,10,12,14]$. Giving support can have a favourable effect on family caregivers but on the other hand it may be emotionally and physically exhausting $[7,13]$. However, receiving support from others (formal or informal sources) may play a key role to help cope throughout the course of the illness and to reduce family caregiver stress $[10,12]$. Nevertheless, the social support can have a negative effect when it doesn't meet the caregivers' needs and when it is felt to be imposed. The perceived availability of support may also have a positive effect even if the recipient doesn't benefit [12]. It is important to support the caregiver responding to the challenge of caring for a terminally ill person [4].

A recent systematic review of primary studies about received and provided social support [12] has shown that the focus since 1970 has been on the quantitative analysis of the informal support. In this study using a qualitative methodology, we focused on the experience of family caregivers in regard to their perceptions of given and received (formal and informal) support while caring for a terminally ill person. The objectives of this study are (1) to identify acts related to the given and received social (formal or informal) support while taking care of a terminally ill person and (2) to describe the relevant aspects influencing the balance between given and received support on the perceived experience of the family caregivers in a palliative care context.

\section{Method}

\section{Setting and sample}

The data reported here were first gathered for a prior need assessment study about palliative care offered by a Montreal Health and Social Services Centre (CSSS) to the population of its territory. The original study (produced for exclusive use within the continuous improvement program) included data from different sources (family and professional caregiver's interviews, a cross-sectional survey and medical records) and involved a thematic analysis of qualitative data to identify the need of family caregivers according to Bradshaw's taxonomy [27]. This secondary analysis of the qualitative data only focused on the analysis of the 23 interviews of caregivers who cared for a terminally ill person at home and/or in a specialized unit of palliative care ${ }^{2}$ in order to explore the perceived balance between given and received support.

Caregivers were originally selected according to the following inclusion criteria: 1) have benefited from palliative care services at home and/or in a specialized palliative care unit within the territory of the CSSS; 2) listed as the principal caregiver in the patient's medical records; 3) provided care of the terminally ill person in the last 3 to 6 months; and 4) willing to participate in a face-to-face interview. Initial contact was through a questionnaire delivered by hand to family members during the episode of care

and "informal" describe the source of the support.

2 Note that only one person died at home 
or mailed to bereaved family caregivers later. We received $45 \%$ of the distributed questionnaires.

Between December 2012 and February 2013, 18 women and 5 men participated: spouses (10), children (7), sisters (4), nieces (1) and sons-in-law (1). All of these family members cared for cancer patients except for one with end-stage renal disease.

The study was approved by the executive director of the institution and conducted in the context of the legal mandate of the governmental act respecting health services and social services and in accordance with the ethical standards of the university institution. The participants were clearly informed that their participation was voluntary and that no names or identifying features were needed [28,29].

\section{Data collection}

Concepts from the literature were used to develop an openended interview guide [30-33]. They included the evolution of the disease, the experience with care and death, the experience with palliative care services, the needs of caregivers, the social and cultural aspects of given and received support and the interaction with the formal and informal network. The researchers pretested the interview guide and the first interviews demonstrated that it was satisfactory as no major incomprehension has been noticed.

\section{Interview procedure}

Interviews were conducted by an anthropologist (first author) at the caregiver's chosen place, usually in Montreal, in a café or at their home; in either French or English; and lasted from 30 to 120 minutes.

\section{Data analysis}

An iterative approach involving researcher debriefings, literature review and data analysis empowered the development of an analysis model based on social support. All interviews were recorded (with consent) and integrally transcript by the same experienced clerical assistant. The researchers analyzed the content of each interview using the written transcript and the NVivo Software ${ }^{\varpi}$.

The authors first explored the data in order to enhance their understanding of the caregivers' experience. We chose to use a thematic analysis [34] focusing on the social support to guide the development of a preliminary model (Figure 1) derived from data but supported by literature. The emerging themes, included in the model, insured that they fit for both palliative services at home and those in a specialized unit. In addition to the data codification according to the model, a descriptive analysis of given and received support was made. We used: 1) a descriptive approach to code the acts of giving and receiving support while caring for a terminally ill person in reference to the literature and according to the different types and sources of support; and 2) an inductive grounded theory approach to explore the aspects influencing the balance of given and received support reported by family caregivers. After the analysis of 12 interviews, all reviewed and discussed by the authors, the retained model was approved. The remaining 11 interviews were subsequently used to validate the final model.

\section{Results}

Table 1 lists the relevant descriptive themes revealed by the interviews and reported as being the support needed. These themes were classified in the three social support types and their possible sources. It also indicated that support was provided by the family caregivers to the terminally ill person or received by the family caregivers from the ill person as well as their informal and formal networks.

Figure 1 shows the simplified developed model which explains how several aspects of given and received support modulate caregiver's perceptions of their experience. Continuous balancing between given and received support was explored. It was revealed that the perceived quality and availability of the received support helped to face the course of illness better than the quantity of the support. The family caregivers self-reported

Table 1: Given and received support in palliative care context.

\begin{tabular}{|c|c|}
\hline Given support & Received support \\
\hline \multicolumn{2}{|l|}{ Instrumental } \\
\hline $\begin{array}{l}\text { - Provision of medical and } \\
\text { practical care, including drug } \\
\text { delivery } \\
\text { - Continuous assistance } \\
\text { - Support coordination } \\
\text { - Home reorganisation } \\
\text { - Tasks of daily living } \\
\text { - Provision of hygienic care } \\
\text { - Visit to hospital while } \\
\text { under treatment } \\
\text { - Visit to palliative care unit }\end{array}$ & $\begin{array}{l}\text { From the ill person } \\
\text { - Practical tasks (bank account, funeral...) } \\
\text { From the informal network } \\
\text { - Tasks of daily living } \\
\text { - Home visits } \\
\text { From the formal network } \\
\text { - Provision of medical and practical care, } \\
\text { including drug delivery } \\
\text { - Home care visits } \\
\text { - Equipment loans } \\
\text { - Services coordination } \\
\text { - Pharmacy services } \\
\text { - Respite } \\
\text { - Delivery of meals on wheels } \\
\text { - Transport }\end{array}$ \\
\hline \multicolumn{2}{|l|}{ Emotional } \\
\hline $\begin{array}{l}\text { - Patient end-of-life accom- } \\
\text { paniment } \\
\text { - Need's identification and } \\
\text { understanding } \\
\text { - Preservation of human } \\
\text { dignity } \\
\text { - Handling the patient's emo- } \\
\text { tional distress } \\
\text { - Handling the family's emo- } \\
\text { tional distress } \\
\text { - Respecting self-limits } \\
\text { - Decision making }\end{array}$ & $\begin{array}{l}\text { From the ill person } \\
\text { - Need's identification and sharing } \\
\text { - Accompaniment of the caregiver in his } \\
\text { or her emotional distress. } \\
\text { From the informal network } \\
\text { - Patient personal assistance } \\
\text { - Caregiver personal assistance } \\
\text { - Being present } \\
\text { From the formal network } \\
\text { - Professional assistance to help with } \\
\text { family's emotional distress, bereavement } \\
\text { - Caregiver's inclusion in decision } \\
\text { making } \\
\text { - Respect of beliefs and values } \\
\text { - Small gestures to the patient }\end{array}$ \\
\hline \multicolumn{2}{|l|}{ Informational } \\
\hline $\begin{array}{l}\text { - Asking, taking and giving } \\
\text { the information } \\
\text { - Defending the patients' } \\
\text { rights }\end{array}$ & $\begin{array}{l}\text { From the formal network } \\
\text { - Information of the course of the illness } \\
\text { and the care. } \\
\text { - Information of the existing services and } \\
\text { how they access to those services. } \\
\text { - Information for decision making } \\
\text { process. }\end{array}$ \\
\hline
\end{tabular}




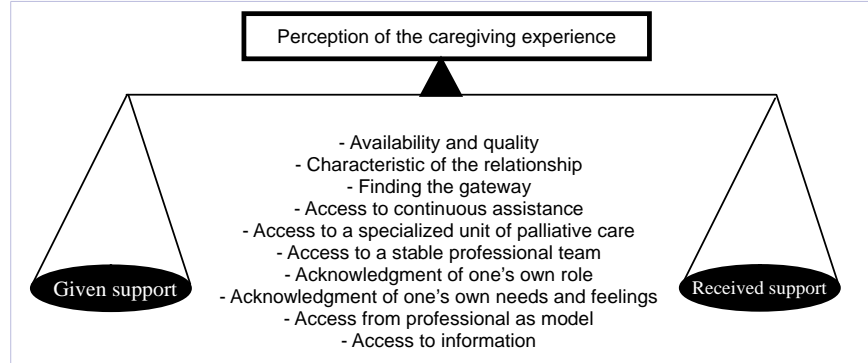

Figure 1: Balance between given and received support.

their own perceptions of both kinds of support. The perceived balance between the different aspects of received and given support may influence the perception of the caregiver regarding their past experience and may present significant links with their capacity to cope and the well-being of the family caregiver.

The quality of the given and received support, as well as the balance between them, was assessed by the researchers according to what was expressed in the interviews and exchanges.

\section{Availability and quality of support}

Some family caregivers had optimal informal support for instrumental activities of daily living. It had improved the quality of given support and had a positive perceived effect on the endof-life experience as evidenced below by the spouse of a patient:

I can't do everything by myself, to look for drugs at the store, to do the housework, to go shopping. Somebody from outside should do it if I want to take care of the ill person. [...] It's important to say it, I was well looked after.

However, when the informal network appeared to be weak or isolated from the situation, the family caregivers felt physical emptiness. They sometimes wished for someone to support them and the terminally ill person as reported by another spouse:

Ifelt lonely because my family lives far from me. Probably, what I missed most was my husband's family. If his family had come to see him, I would have had a little respite, I would have been happy for him.

Sharing responsibilities with a member of the informal network helped to ease the burden of balancing end-of-life care and family activities. One caregiver recognized her father's support:

I am grateful I had my father living with my two kids and me. We used to exchange roles "Dad, go get the kids for me, make them do their homework, I'll go see my aunt today". So when I got home, my kids had done their homework and were asleep.

An informal network allowed caregivers to enjoy some freedom in the choice of their role and activities. Relying on others for continuous assistance to the patient helped caregivers to respect their limits and benefited them in terms of health and well-being. A spouse explained her situation:

I have been a member of a musical theatre group for thirteen years, every Friday. I never missed a rehearsal. I forget everything while singing. It was really important. My sister-in-law came to stay with my husband. Otherwise, it was my husband's friends who took the occasion to spend time with him.

\section{Characteristics of the relationship}

Frequently, caregivers thought that they could manage the situation by themselves. However, when they realised the burden of care, some of them looked for assistance in their informal network. They sought someone they could trust. In this situation, the request was usually accepted. A husband talked about his sister-in-law's help:

I had help from my sister-in-law. At first, I thought I'd be able to manage everything by myself but it was a lot of different things. I had to cook food. It was not only taking care of her. I asked her sister "would you come to cook dinner?" She answered "I'll move to your place".

Caregivers noted the importance of informal support in terms of friendship assistance to the ill person. A woman explained that visits from friends offered a little respite from the sickness to her ill husband and herself:

We had a lot of visits from friends. I think he saw everybody he used to know. I liked when people came because it changed his mind a little bit. He had the impression of no longer being an ill person.

An informal social network is also reported to provide important support for the bereavement. Caregivers mentioned the need to share memories with others who used to know them as reported by this spouse:

I would have liked having somebody to talk about him, to remember anecdotes of him when he was younger, or whatever. If we find people to talk with, at least, it helps.

At the same time, family caregivers have experienced inadequate support from members of their informal network and have been profoundly affected by stress and loneliness. The support given to the patient may generate family conflict where disagreements emerge about the way of caring. A woman taking care of her mother explained her difficulty in handling her brother's rebukes:

At home, I have to say that I experienced the situation by myself. [...] My brother was way more difficult to handle than my sick mother. I didn't ask him for help because he disagreed about my mother living at my home. All the time, I got a pile of crap from him. He wasn't there to offer me support.

Given the fact that the informal network is also affected by the end-of-life of an ill person, family caregivers may have difficulty finding somebody to rely on to share the burden of care, as reported by a spouse:

It is not easy to find people to help you. Your relatives, your family and your friends, it's really hard for them too. They are not able to prepare you for what comes next, to prepare me for my husband's death. 
Some caregivers shared the evolution of their relationship with the ill person during the course of their illness. The reciprocity of the relationship characterized the end-of-life experience and the caregiver's capacity to cope. Mutual support helped to face the reality of the future loss. A daughter reported how her mother faced her end-of-life process:

And she helped us. "Don't cry, you do not have to cry. I made the decision, I am really conscious of that and I am happy with it." She consoled everybody.

Moreover, when the patient accepts his or her own fate, the experience seems to be less oppressive. A man recounted the reaction of his mother-in-law at the end of her life:

It was something she thought over. She was satisfied with her decision to die. During the two weeks before her death, she never came back on her decision. She was happy. "I made my decision, and it happens to us all. During this time, let's have fun."

A formal health and social network takes a big place in the balance of given and received support. Family caregivers identified key aspects which characterised support in the course of the caring experience.

\section{Finding the gateway}

The accessibility of services is something commented on by family caregivers. Availability of palliative care support services offered by the CLSC is facilitated if a cancer diagnosis is given by the hospital. The hospital establishes a quick liaison with the CLSC which will start the home-based palliative care without much delay. Nevertheless, the services were not quite as accessible for the increasingly dependent elderly. Diagnosis and terminal prognosis are often the criteria for access to palliative care services at home or in a specialized unit as experienced by a daughter taking care of her mother:

We were supposed to get the diagnosis on November 20. In fact, my mother died that day. We wanted to go to a specialized palliative care unit, but we needed the official diagnosis to do so. We went to the doctor at the end of October and we pushed to get a quick diagnosis. He [doctor] gave us the diagnosis, a stomach cancer, end-stage. He said "She has 2 or 3 weeks to live". She came back to my home for two days, which was the time to find a place in a palliative care unit.

However, all caregivers reported to have found the gateway to appropriate services at the hospital. The fact is when she got to the hospital; she began to be taken care of by the system. This was good for us.

\section{Access to continuous assistance and care}

Availability of 24-hour professional services was reported as a source of valuable support at home, but also in specialized palliative care units. These services were helpful in providing information or managing equipment and periods of emotional distress, as expressed by this spouse:

He had an anxiety attack. We had a special 24-hour number. A nurse came from the suburbs at $11 \mathrm{pm}$ and she spent half an hour with him. When she left home, I could go to bed.
Caregivers mentioned having benefited from a 24-hour professional back-up in the specialized unit. However, homebased palliative care would benefit from 24 hours professional services. In fact, that need is greater when symptoms worsen. It was especially reported as an important problem in emergency situations during week-ends and public holidays. A caregiver explained her difficulty in getting services during holidays:

And then, his health condition deteriorated on Friday, the Easter Friday. It is a public holiday, I wasn't able to reach any professional. That was a problem.

Some of them stated that the lack of accessibility in those particularly distressful periods ended with the use of emergency facilities. A daughter explained her discussion with the paramedics after her mother called them while waiting for nursing assistance at her home:

"No, no, no, she does not have to go to the hospital, the nurse is coming" [...] In the end, she went to the hospital. I thought that the nurse was to arrive at home early in the morning. I thought she said 9 or half past 9 [AM] because she [mother] wasn't feeling great and was a priority. She arrived at half past 11 [AM], my mother was already at the hospital.

Those situations are usually stressful and are reported as causing a feeling of powerlessness, anxiety, guilt and self-blame.

Access to a trusted professional was facilitated in the palliative care unit. At home, even if the family caregivers had 24-hour access to phone assistance, they highlighted a significant difference between the two services and in their perception of security and comfort.

Each time we call the CLSC, of course, they react. They will come but not right away. [...] At the palliative care unit, as soon as we rang for the nurse, she immediately came or called the doctor. It was incredible! [...] She was always there, when we asked for something, she was always there.

Moving from home-based palliative care to a specialized unit is linked with a change in the caregiver's given support. Some stated that, it was at that time that they achieved their role of accompanying at the end-of-life to the fullest. They were completely focused on the ill person. Other tasks were done by the health workers. A spouse told of her experience:

As I said, at home it was more difficult. To be honest, I drew farther away from him. It was too painful, I guess. [...] I began to realize how it was when we got to the palliative care unit. There, I was able to talk to him. [...] At home, it was too difficult. I am happy to have benefited from this week at the hospital. Even if my husband was sleepy, for me it was my week to be close to him.

Finally, the family caregiver found herself comfortable in her chosen role and her new responsibilities. It is weird to say but it was a great experience.

Family caregivers who witnessed the ill person's distress may have felt powerless and sometimes guilty especially if they had not received the proper professional assistance or were unable to comfort the person using their own resources, as reported by the niece of a terminally ill woman: 
Sometimes, when she was in her bed, she began to cling to it and shouted "help me, help me, help me". They were the most difficult moments for us, to see her like that.

\section{Access to a specialized unit of palliative care}

Support offered in the palliative care unit seems to provide comprehensive continuing care. As mentioned above, the family caregiver focused on giving support to the ill person and on preparing themselves for the final loss. A daughter expressed her experience in a palliative care unit: At that time, high quality care was provided. We no longer needed to take care of anything else except her.

The changed role of the family caregiver can occur only if they have access to a palliative care unit for a significant period. Our observations show that a short period in a palliative care unit was generally not sufficient to establish supportive care. In these cases, the unit is perceived as a dying place. A husband explained his last memories with emotion.

I could have had some great moments. The only image I have left, it is of my wife making a grimace while receiving a shot from the nurse. It is the last vital sign I remember. She was at the palliative care unit for three days.

Access to a palliative care unit for a relatively significant period is reported to restore a feeling of safety among family caregivers and patients. Availability and proximity of professional assistance promotes psychological well-being among family members, allowing them to take time to rest and to support the ill person the way they would like to. Furthermore, a professional could answer their demands at any time of day or night. I told myself, if she is admitted [to the palliative care unit] it will be a great relief. She will feel safe.

\section{Access to a stable professional team}

Regular and stable support offered by the same team to family caregivers is highlighted as being important. A bond of trust has to be formed between family caregivers and professionals in order to provide an effective relationship and to create a positive caring experience as reported by a spouse caring for her terminally ill husband at home:

I really appreciated the home-based nurse services from the CLSC. What I appreciated was that it didn't have significant staff turnover. Of course, sometimes she had to take days off but it was always the same substitute.

Furthermore, a stable team created a place for dialogue and exchange. Some caregivers may have felt loved and valued. We became friends because it was always the same nurses. [...] It was amazing.

The opposite situation had negative effects on family caregivers, who witness the emotional distress of the patient. A woman described the feelings of stress experienced by her mother:

Team stability is important. [...] It can be one or two or a maximum of three people for the staff turnover during holidays. It is comforting for the terminally ill person. She never knew who was coming for her care. It brought a stress that she shouldn't have had to live with at the end of her life.

\section{Acknowledgement of one's own role}

The family caregivers' acknowledgement of their role and their limits is fundamental. As remarked, many caregivers wished to give support at their level of competence and to receive support with tasks they were uncomfortable with. It is crucial for caregivers to have the freedom to give medical care or not, and to be supported in it. A spouse admitted her difficulties about medical care:

He [doctor] said: "[...] you can give him his shot wherever". I said "no, no, no, no, no, no, no." I started to cry. I said "No, I don't want to make him suffer, he already suffers enough, I don't want to do it." [Doctor] "Ok madam, we will try something else."

Family caregivers who have some professional training do not always feel comfortable giving medical care. A spouse, a professional nurse, explained her feelings about given support: "I didn't want to do it anymore, he wasn't my patient, he was my husband." However, caregivers reported that they appreciated when they were recognized for their knowledge and their caring approach. "The staff used to involve me in the caring; they knew what I was used to. They understood, it was alright."

\section{Acknowledgement of one's own needs and feelings}

Family caregivers reported the need for support by professionals to face the duration of the illness. The evaluation of patient and family caregiver needs, in terms of professional support, has to take the "unknown" characteristic of the situation into account. The lack of understanding of their needs of the endof-life context makes them vulnerable. A spouse explained her first meeting with the home-based nurse:

When the nurse first came to see us she asked "What do you need for your home? Do you need a bed?" [Laughs] "No, we don't need a bed," I replied. But in reality, yes we needed a bed. I wasn't well prepared for what we were going to go through.

Many caregivers shared their refusal to participate in formal meetings for emotional support during the caring. They argued their inability to benefit from those meetings, especially during the core moment of end-stage illness as reported by a spouse:

I think they tried to reach us, but my husband didn't want to talk with anybody and me, I wasn't there. I couldn't, I had too many things and would take care of myself later on.

Moreover, professional support as far as the family caregiver's general health or feelings was much appreciated. She [nurse] would come patting my back "how are you?". I felt a lot of empathy from her. Emotional support is operationalized when trusted relationships had emerged and could be felt through professional manners and little gestures to the patient, as reported by a woman taking care of her sister:

One day, I got to my sister's room [in the palliative care unit] and the nurse had put the bed in front of the window, so that she 
could watch the river. It was nice of him to have thought about that. [...] I don't know about the other nurses, but certainly, I will remember him all my life.

An acknowledgement from the patient and the informal network is also reported to have an important role to play to help caregivers give support. Some caregivers highlighted the burden associated with the perception of being the pillar of the family when nobody seemed to care about them. A woman spoke of her feelings about her family:

We are all human beings. We all need attention from others, to talk. It made me realize that in the past, I always took care of everyone. "How are you, don't stay alone..." But nobody ever did that for me.

\section{Access to a professional as model}

Formal support offers a model to the family caregiver. Some of them observed professionals in action and reproduced some of the techniques for the given support. Those models may have enhanced caregivers' competence and improved their selfesteem as demonstrated by a caregiver:

I was aware of the professional support. When there were some tasks that you don't really know about... I didn't have any training. How to get my mother up without hurting her? When the providers helped me, I learned tricks. I think it is important to benefit from professional competence.

Professionals in palliative care were seen to act with empathy and also with calm and gentleness. Small gestures to the patient helped keep a perceived positive experience at the end-of-life.

Nurses, they know how to give shots and drugs. The most important is how it is done, how they approach you, how they respect you. It was always nice, always kind. Mimi [a nurse] always came to give relaxing massages to my mother at the end of her shift.

\section{Access to information}

Information related support is needed by the family caregivers to face the unknown course of end-stage illness. They expected to be informed of the reality that they would go through. Being informed by the professionals about the different stages of illness is supportive. This following comment shows it well:

If you are in denial, OK it's your reality, but just a guide to explain what will happen next and that you have to prepare yourself is a good idea. Because if I had known... I don't think I would have used home-based palliative care for my husband. It would have been so different. [...] I needed to have more input about the different services.

Support information about death may relieve caregivers' guilt and pain and facilitate an exchange with the ill person that the caregiver hoped for.

I learned something afterward. A friend of mine told me that when he was caring for his wife, they had access to a social worker. $\mathrm{He}$ [social worker] talked with both of them, to the wife and to the husband. He made them ready for death. I think I would have loved to have that. It would have opened us up to talk about it. We didn't talk about it at all.

Information about the dying and agony process is mentioned as necessary and as supportive.

Family caregivers valued information about existing services to meet different needs, especially at the final stage of the illness. Palliative care services were sometimes unknown to the caregivers or their concerns about the care were too heavy to remember their existence. A spouse explained how she forgot about the existence of palliative care services:

I would have loved to have home-based palliative care services. But I didn't know. As I told you, he [her husband] was quite fine when he wasn't vomiting. But it went so fast at the end. I didn't have time... I was too busy taking care of him, it was so intense. I had forgotten to ask the CLSC for home-based palliative care services.

Information about prognosis had to be detailed. Caregivers reported being informed about the 3-month prognosis. They expected to have 3 months left with the ill person. When it was shortened, caregivers had difficulty in understanding what happened, as evidenced by a family caregiver:

The hardest times were at the palliative care unit. She stayed there for a week. We didn't think it would go so fast because they [providers] told us she still had two or three months left. It didn't make sense to us, but that was it. [...]

When death came faster, family caregivers reported feeling that the palliative care received was similar to euthanasia, and they felt guilty having accepted such care. This perception was reinforced when professionals provided continuous sedation to relieve the patient's pain.

I didn't expect that my sister was going to die when she got to the palliative care unit. Of course, I knew that she was going to die but that fast? I thought it was natural death. "She has been getting shots", everybody said. Ok fine, stop telling me, now I know.

This difficulty represents a real obstacle to the mourning process.

\section{Discussion}

This study shows that caring for a terminally ill person requires continuous balancing between given and received support to ease the caregiver's experience. The results have identified the aspects affecting the balance between given and received support and the ability of the caregiver to keep a positive perception of the lived experience. As shown in other studies [12] the availability and the quality of the relationship with the informal network can positively or negatively influence the perceived experience of care by family caregivers. Moreover, as reported by Schwarzer and Knoll [10], coping is facilitated by the availability of the support. The perceived social support may generate a positive effect if it is associated with a higher perceived self-efficacy to respond to the caring situation. The results of this study revealed that in a palliative care context, the different aspects shown in Figure 1 impact the balance and 
influence positively or negatively the caregivers' experience. It is especially true for the perception of support provided by the formal sources in terms of accessibility and availability of the services. The perceived formal social support seemed to influence the way the family caregiver assumed their role of giving support and their perception of the lived experience.

Caregivers' acknowledgement of their assumed role, their feelings and their needs is fundamental $[9,24,35]$. When the formal and informal networks and the ill person confronted this challenge, the family caregiver felt a sense of accomplishment. Some studies show that preparing family caregivers to care for a dying person should begin at the first meeting (Hudson, Aranda, \& Kristjanson, 2004). Moreover, the need of family caregivers to face their emotional distress was profoundly filled once they received special attention from a trusted professional. That feeling was also mentioned when the interventions provided by professionals involved empathy and gentleness. Many studies show the same results [9,27,35-38]. According to Weibull et al. [9], caregivers seem to cope better if they perceived sufficient support during the caring period [34]. Frequent visits to the patient and their family, control of distressing symptoms, provision of standard resources such as nursing care and equipment are fundamental [37]. Information about the course of illness, the management of care and about the death process is also seen as supportive for some caregivers. Difficulties can be avoided when family caregivers are better informed and equipped to address the proper care for their relative. The dying process was lived as the hardest moment of the end-of-life accompaniment. Providers should make the information about agony available to the family caregivers to help them better understand the normal process of death $[35,39]$.

Some caregivers highlighted their need to keep in touch with the known and trusted professionals and to benefit from followup discussions about what they were facing [40]. Transition from home care to the palliative care unit or to death was more difficult without a trusted professional to refer to. A strong relationship can be a significant source of support, especially when trusted providers stay in the picture as long as needed.

Access to a palliative care unit for a significant period before death relieved the caregiver of the burden and supported wellbeing. Professional assistance provided a strong sense of security for the family caregivers and the ill person. The patient was seen to be in good hands, and this perception helped caregivers to take some respite and gave them energy to deal with the last stages. A short stay may restrict the time available to implement supportive strategies for the family and caregivers [37]. Moreover, short hospitalisation may be associated with the perception of endorsing euthanasia practices and with a strong feeling of guilt from the inability to care for the patient at home.

Some caregivers reported difficulty accepting the patient's death. According to them, death was hastened by pain-relieving medications used in the palliative care unit. Terminal prognosis provided by medical professionals in the studied settings is generally three months or less. Caregivers expected to spend this time with their ill relative and to get ready for their loss [40].
Unfortunately, the reality suggested something else. As reported by caregivers, the patient's death occurred within a few days, for others, a few weeks. Moreover, some family caregivers reported they had hoped for an improvement in the patient's health after the medical professional's first meeting in the palliative care setting. Hope is important to get through the caregiving experience, but unrealistic hope may produce guilt, sadness and incomprehension of the situation afterwards. This subject should be further investigated.

One of the most highlighted aspects in the balance is the availability of 24-hour professional back-up services [9,8,32,38]. The ambulatory shift increased home-based caring and reinforced a dumbing-down of care. The responsibility of the patient is shared between family caregivers and professionals, despite the unbalanced responsibility load existing between them. However, support by professionals should be offered as needed given the emotional involvement of family caregivers and their lack of medical knowledge. Budgetary restrictions should not force family caregivers to manage the situation by themselves $[8,37]$.

Social support is strongly enhanced by an informal network [9]. Received support allows the caregiver to give quality care to the ill person. This may enhance the caregivers' capacity to cope while caring and may provide them positive perceptions according to their past experience. Available assistance from others helped the caregivers see themselves as acknowledged, valued, respected, trusted and loved. Although a few caregivers reported negative effects from their informal support, it was generally limited to one person. Based on this research, one of the important roles that a palliative care team can play is to identify dysfunctional relationships between family members and support them facing the end-of-life stage $[14,8,36]$.

The strength of this study lies in the originality of linking caregivers' various experiences to a model of social support. This is especially so as much of the literature on family caregiving in palliative care to date, is not grounded in a strong theoretical framework and is generally centred on the burden they experience. We sought to understand the given support as well as the received support in a palliative care context that influences the perceived experience of caregiving. This study also focused on different settings and trajectories of care. The list of tasks in Table 1 might be useful in the continuous improvement of training for different settings in palliative care and to identify the needs of caregivers.

Amongst the limitations was the length of time after the loss of the care recipient. Family caregivers participated in this study from 3 to 6 months after the loss of their relatives. Further research could be carried out over a longer period after the loss to explore the possible impact and applicability of the findings. Furthermore, although this project was done in a multicultural neighbourhood, only a few immigrants agreed to be interviewed, this limiting the generalizability of the findings. This could be an area for further research. The inclusion of only cancer-related deaths was also a limiting factor for generalization to other populations. 


\section{Conclusion}

The results show that caring for a terminally ill person requires continuous balancing between given and received support to ease the caregiver's experience. Analysis has identified the aspects affecting the balance between given and received social support and the ability of the caregiver to keep a positive perception of the lived experience. Finding revealed that family caregivers seem to cope better if they perceived sufficient social support during the caring period. These findings might be useful in the continuous improvement of training for different settings in palliative care and to focus on identifing the needs of caregivers.

\section{Acknowledgement}

We are grateful to family caregivers who generously gave their time and intimate stories about their caregiving experience and the loss of their relatives. We also want to thank medical, health and social professionals and volunteers from the studied palliative care settings for their participation. This paper was financed by the Centre de recherche et de partage des savoirs InterActions of the CSSS de Bordeaux-Cartierville-Saint-Laurent, affiliated to the Université de Montréal. The authors thank Bruce Charles Bezeau and Jesse Burns for the English revision of the manuscript.

\section{References}

1. Gagnon E, Guberman E, Côté D, Gilbert C, Thivierge N, Tremblay, M Les impacts du virage ambulatoire: responsabilité et encadrement dansla dispensation des soins à domicile. Ottawa, Ontario: Fondation canadienne de la recherche sur les services de santé.

2. Lavoie JP, Guberman N. Le partenariat professionel - famille dans les soins aux personnes âgées. Un enjeu de reconnaissance. Lien social et politiques. 2009; 62: 137-148.

3. Tousignant $M$, Dubuc $N$, Hébert $R$, Coulombe C. Home-care programmes for older adults with disabilities in Canada: how can we assess the adequacy of services provided compared with the needs of users? Health Soc Care Community. 2007; 15(1):1-7. doi: 10.1111/j.1365-2524.2006.00645.x.

4. Carlsson ME, Rollison B. A comparison of patients dying at home and patients dying at a hospice: sociodemographic factors and caregivers' experiences. Palliat Support Care. 2003; 1(1):33-9.

5. Munday D, Dale J, Murray S. Choice and place of death: individual preferences, uncertainty, and the availability of care. J R Soc Med. 2007; 100(5):211-5.

6. Payne S, Smith P, Dean S. Identifying the concerns of informal carers in palliative care. Palliat Med. 1999; 13(1):37-44.

7. Kristjanson LJ, Aoun S. Palliative care for families: remembering the hidden patients. Can J Psychiatry. 2004; 49(6):359-65.

8. Brazil K, Bainbridge D, Rodriguez C. The stress process in palliative cancer care: a qualitative study on informal caregiving and its implication for the delivery of care. Am J Hosp Palliat Care. 2010; 27(2):111-6. Doi: 10.1177/1049909109350176.

9. Weibull A, Olesen F, Neergaard MA. Caregivers' active role in palliative home care - to encourage or to dissuade? A qualitative descriptive study. BMC Palliative Care. 2008 7, 15.
10. Schwarzer R, Knoll N. Functional roles of social support within the stress and coping process: A theoretical and empirical overview. International Journal of Psychology. 2007; 42(4):243-52.

11. Dumont I, Dumont S, Mongeau S. End-of-Life Care and the Grieving Process: Family Caregivers Who Have Experienced the Loss of a Terminal-Phase Cancer Patient. Qual Health Res. 2008; 18(8):104961.

12. Nurullah AS. Received and Provided Social Support: A Review of Current Evidence and Future Directions [Internet]. Rochester, NY: Social Science Research Network, 2012.

13. Lu L, Argyle M. Receiving and giving support: Effects on relationships and well-being. Counselling Psychology Quarterly. 1992; 5(2):123-33.

14. Cain R, MacLean M, Sellick S. Giving support and getting help: informal caregivers' experiences with palliative care services. Palliat Support Care. 2004; 2(3):265-72.

15. Uchino BN, Carlisle M, Birmingham W, Vaughn AA. Social support and the reactivity hypothesis: conceptual issues in examining the efficacy of received support during acute psychological stress. Biol Psychol. 2011; 86(2):137-42. doi: 10.1016/j.biopsycho.2010.04.003.

16. Minister of Health and social services (MSSS). Quebec end-of-life palliative care policy. Government of Quebec, 2004; 98.

17.Leclerc, B-S., Lessard, S, Blanchard, L., Cantinotti, M., Couturier, Y., Gervais, D., Mongeau, S. (2014a). Interdisciplinarité en pratique clinique de soins palliatifs de fin de vie : efficacité et degré d'intégration. InterActions, Centre de recherche et de partage des savoirs, CSSS de Bordeaux-Cartierville-Saint-Laurent CAU.

18. The Pan-Canadian Gold Standard for Palliative Home Care - Download [Internet]. CHPCA Marketplace/Marché. [cited 2014 Oct 20].

19. Leclerc B-S, Lessard S, Bechennec C, Le Gal E, Benoit S, Bellerose L. Attitudes toward death, dying, end-of-life palliative care, and interdisciplinary practice in long term care workers. J Am Med Dir Assoc. 2014;15(3):207-13. doi: 10.1016/j.jamda.2013.11.017

20. Canadian Hospice Palliative Care Association. A Model to Guide Hospice Palliative Care. Ottawa, ON: Canadian Hospice Palliative Care Association. 2013; 25.

21. Langford CP, Bowsher J, Maloney JP, Lillis PP. Social support: a conceptual analysis. J Adv Nurs. 1997; 25(1):95-100.

22. Devault $A$, UniversiteÌ du QueÌbec aÌ€ Hull, UniversiteÌ du Quel̀bec en Outaouais. Le soutien social et l'intervention de nature psychosociale ou communautaire. Hull: Universitel̀ du QueÌbec en Outaouais, [Groupe d'eltude et de recherche en intervention sociale.

23. Proot IM, Abu-Saad HH, Crebolder HFJM, Goldsteen M, Luker KA, Widdershoven GAM. Vulnerability of family caregivers in terminal palliative care at home; balancing between burden and capacity. Scand J Caring Sci. 2003; 17(2):113-21.

24. Hauser JM, Kramer BJ. Family caregivers in palliative care. Clin Geriatr Med. 2004; 20(4):671-88. doi: 10.1016/j.cger.2004.07.003.

25. Semmer NK, Elfering A, Jacobshagen N, Perrot T, Beehr TA, Boos N. The emotional meaning of instrumental social support. International Journal of Stress Management. 2008; 15(3):235-51. doi: 10.1037/1072-5245.15.3.235.

26. Ministère de la Santé et de Services sociaux (MSSS). Note 1 Note de clarification relative aux compétences matérielle et territoriale des comités d'éthique de la recherche. Direction générale adjointe de l'évaluation, de la recherche et des affaires extérieures, Unité de l'éthique, Gouvernement du Québec. 2007. 
27. Robison J, Shugrue N, Porter M, Fortinsky RH, Curry LA. Transition from home care to nursing home: unmet needs in a home- and community-based program for older adults. J Aging Soc Policy. 2012;24(3):251-70. doi: 10.1080/08959420.2012.676315.

28. Kemp C. Cultural issues in palliative care. Seminars in Oncology Nursing [Internet]. 2005; 21(1):44-52.

29. Mitchell D. Spiritual and cultural issues at the end of life. Medicine [Internet]. $2008 ; 36(2): 109-10$.

30. Ducharme F, Vissandjee B, Paquet M, Carpentier N, Lévesque L, Trudeau D. La pratique dans un contexte pluriethnique: Démarche en vue de la création d'une approche de négociation entre le personnel des services de soutien à domicile et les proches-aidantes d'un parent âgé. Nouvelles pratiques sociales. 2009; 21(2):137. doi: 10.7202/038967ar.

31. Donovan R, Williams A, Stajduhar K, Brazil K, Marshall D. The influence of culture on home-based family caregiving at end-of-life: a case study of Dutch reformed family care givers in Ontario, Canada. Soc Sci Med. 2011 Feb; 72(3):338-46. doi: 10.1016/j.socscimed.2010.10.010.

32. Guest G, MacQueen K, Namey E Applied thenamtic analysis. California Sage Publications, 320. doi: 10.1016/j.socscimed.2010.10.010.

33. Harding R, Higginson IJ. What is the best way to help caregivers in cancer and palliative care? A systematic literature review of interventions and their effectiveness. Palliat Med. 2003; 17(1): 63-74.

34. Mangan PA, Taylor KL, Yabroff KR, Fleming DA, Ingham JM. Caregiving near the end of life: unmet needs and potential solutions. Palliat Support Care. 2003; 1(3):247-59.

35. Hudson PL, Aranda S, Kristjanson LJ. Meeting the supportive needs of family caregivers in palliative care: challenges for health professionals. J Palliat Med. 2004; 7(1): 19-25.

36. Stajduhar KI. Examining the perspectives of family members involved in the delivery of palliative care at home. J Palliat Care. 2003; 19(1): 27-35.

37. Foucault C, Mongeau, S. Les besoins psychosociaux: comprendre l'expérience des proches et les accompagner. In C. Foucault (Ed.), L'art de soigner en soins palliatifs. Perspectives infirmières. Montréal: Presse de l’Université de Montréal.

38. Jansma FFI, Schure LM, de Jong BM. Support requirements for caregivers of patients with palliative cancer. Patient Educ Couns. 2005; 58(2): 182-6. doi: 10.1016/j.pec.2004.08.008.

39. Rhodes P, Shaw S. Informal care and terminal illness. Health Soc Care Community. 1999; 7(1): 39-50.

40. Bradshaw J. A taxonomy of social need. New Society. 1972; 30(3), 72. 